\title{
Widget, Widget on the Wall, Am I Performing Well at All?
}

\author{
Citation for published version (APA):
}

Scheffel, M., Drachsler, H., de Kraker, J., Kreijns, K., Slootmaker, A., \& Specht, M. (2017). Widget, Widget on the Wall, Am I Performing Well at All? IEEE Transactions on Learning Technologies, 10(1), 42-52.

https://doi.org/10.1109/TLT.2016.2622268

DOI:

10.1109/TLT.2016.2622268

Document status and date:

Published: 01/01/2017

Document Version:

Peer reviewed version

\section{Document license:}

CC BY-NC-ND

Please check the document version of this publication:

- A submitted manuscript is the version of the article upon submission and before peer-review. There can be important differences between the submitted version and the official published version of record. People interested in the research are advised to contact the author for the final version of the publication, or visit the DOI to the publisher's website.

- The final author version and the galley proof are versions of the publication after peer review.

- The final published version features the final layout of the paper including the volume, issue and page numbers.

Link to publication

\section{General rights}

Copyright and moral rights for the publications made accessible in the public portal are retained by the authors and/or other copyright owners and it is a condition of accessing publications that users recognise and abide by the legal requirements associated with these rights.

- Users may download and print one copy of any publication from the public portal for the purpose of private study or research.

- You may not further distribute the material or use it for any profit-making activity or commercial gain

- You may freely distribute the URL identifying the publication in the public portal.

If the publication is distributed under the terms of Article 25fa of the Dutch Copyright Act, indicated by the "Taverne" license above, please follow below link for the End User Agreement:

https://www.ou.nl/taverne-agreement

Take down policy

If you believe that this document breaches copyright please contact us at:

pure-support@ou.nl

providing details and we will investigate your claim.

Downloaded from https://research.ou.nl/ on date: 26 Apr. 2023 


\title{
Widget, widget on the wall, am I performing well at all?
}

\author{
Maren Scheffel, Hendrik Drachsler, Joop de Kraker, Karel Kreijns, Aad Slootmaker, Marcus Specht
}

\begin{abstract}
In collaborative learning environments, students work together on assignments in virtual teams and depend on each other's contribution to achieve their learning objectives. The online learning environment, however, may not only facilitate but also hamper group communication, coordination and collaboration. Group awareness widgets that visualise information about the different group members based on information collected from the individuals can foster awareness and reflection processes within the group. In this paper, we present a formative data study about the predictive power of several indicators of an awareness widget based on automatically logged user data from an online learning environment. In order to test whether the information visualised by the widget is in line with the study outcomes, we instantiated the widget indicators with data from four previous runs of the European Virtual Seminar on Sustainable Development (EVS). We analysed whether the tutor gradings in these previous years correlated with the students' scores calculated for the widget indicators. Furthermore, we tested the predictive power of the widget indicators at various points in time with respect to the final grades of the students. The results of our analysis show that the grades and widget indicator scores are significantly and positively correlated, which provides a useful empirical basis for the development of guidelines for students and tutors on how to interpret the widget's visualisations in live runs.
\end{abstract}

Index Terms-learning analytics, visualisation, group awareness, correlation analysis, regression analysis.

\section{INTRODUCTION}

A LREADY from the early days of online education and e-learning, collaborative learning has been one of the prominent pedagogical approaches. Synchronous and asynchronous communication technologies are employed to enable collaborative learning in small, virtual teams of students. However, mediating all communication, coordination and collaboration through online tools appears to result in suboptimal support of, in particular, the social interaction and the group dynamics among team members [1]. This can lower feelings of social presence [2] and can hamper cognitive processes. One solution is to provide group awareness to students as this might alleviate the problems encountered [3], i.e. to provide explicit information on the activity of group members and to stimulate awareness, reflection and social interaction. Very often, this information is based on data collected via questionnaires or similar forms filled in by the group members themselves [4] which can be time consuming, tedious and disruptive. This process, however, can be automated by including learning analytics based on interaction data automatically collected within the learning environment. While measurements based on behavioural data are not a one-to-one replacement for measurements based on subjective experience, i.e. proximal variables have indeed more predictive power than distal variables [5], learning analytics based on activity data can be used as an additional indication towards group activities that is non-

M. Scheffel, H. Drachsler, J. de Kraker, K. Kreijns, A.Slootmaker and M. Specht are with the Open University of the Netherlands, Valkenburgerweg 177, 6419 AT Heerlen, The Netherlands. Email: maren.scheffel@ou.nl, hendrik.drachsler@ou.nl, joop.dekraker@ou.nl, karel.kreijns@ou.nl,aad.slootmaker@ou.nl,marcus.specht@ou.nl.

H. Drachsler is also with the University of Applied Sciences Zuyd, Nieuw Eyckholt 300, 6419 AT Heerlen, The Netherlands. Email: hendrik.drachsler@zuyd.nl.

Manuscript received $x x x x, 2016$; revised $x x x x, 2016$.

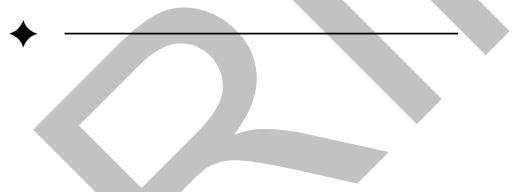

disruptive and covers the whole student population of a course.

Learning analytics (LA) is "the measurement, collection, analysis and reporting of data about learners and their contexts, for purposes of understanding and optimising learning and the environments in which it occurs" as defined in the call for papers of the first international conference on learning analytics and knowledge (LAK) $2011^{1}$ and subsequently taken up by [6]. The field has been growing steadily over the last few years as can be seen by the rising numbers of publications as well as events dedicated to learning analytics [7].

While the term learning analytics may evoke an impression of a field mainly geared towards computing and analysing the collected data to improve outcome, it is indeed about more than that, i.e. a holistic view on the different processes involved in the support and improvement of learning and teaching [8]. The generic framework for learning analytics [9] also shows that the variety of issues in this field is quite diverse, i.e. it covers aspects from stakeholders, objectives, data and technologies to competences and constraints. It is thus important to not simply reduce learning analytics to plain 'number crunching' on an institutional level but to purposefully support the immediately involved stakeholders, i.e. teachers and learners. As Ferguson [10] explains, learning analytics offers "ways for learners to improve and develop while a course is in progress. These analytics do not focus on things that are easy to measure. Instead, they support the development of crucial skills: reflection, collaboration, linking ideas and writing clearly".

A learning analytics widget can provide feedback by visualising the learners' activities within a learning envi-

1. https://tekri.athabascau.ca/analytics/call-papers 
ronment and can thus support awareness and reflection processes. It allows learners as well as teachers to see the learners' current situation and to adapt their behaviour, e.g. learners could decide to participate more while teachers could decide to get in touch with a specific student. Being able to not only project an immediate future status but to also relate the visualised information to a learner's overall outcome of the course could increase the usefulness of such a widget especially with regards to self-regulation as well as collaborative learning.

\subsection{Related Work}

This section reviews related research about the purpose and impact of learning analytics widgets and dashboards as well as research about the predictive power of students' behaviour during a course. The literature presented can roughly be divided into two sections: the theoretical perspective and the practical perspective.

On the theoretical side there are the two crucial aspects of 'awareness' and 'reflection' that need to be taken into account when dealing with learning analytics dashboards and widgets. The reflection on presented analytics results is not possible without awareness which in turn depends on some form of feedback to the user [11], [12]. According to Endsley [13], [14] being aware of one's own situation is a three level process and a prerequisite for making decisions and effectively performing tasks: the perception of elements in the current situation is followed by the comprehension of the current situation which then leads to the projection of a future status. Once a learner is aware of his situation, he "reflects on the phenomenon before him, and on the prior understandings which have been implicit in his behaviour" [15] to then engage in a process of continuous learning. Reflection can promote insight about something that previously went unnoticed [16] and lead to a change in learning or teaching behaviour. Verbert et al. [17] emphasise the importance of these aspects in their process model for learning analytics applications: it consist of the four stages awareness, reflection, sensemaking, and impact.

Awareness, however, is not the only aspect that influences the process of feedback, reflection and behavioural change, i.e. of self-efficacy and self-directed learning [18]. Winne [19] describes self-regulated learning as "principally comprised of knowledge, beliefs, and learned skills, [...] malleable in response to environmental influences" and as something that learners inherently do. Zimmerman [20] adds to this that self-regulated learning is indeed about more than knowledge and skill and that personal influences such as emotions, one's behaviour and one's social environment play an important role. Learners thus have different ways to construct knowledge on the basis of the information given to them when learning in a self-regulated way [21] and can act and react in different ways.

On the practical side there have been various studies about the positive or negative effect of different behaviour during a course on study outcomes. For face-to-face classes in college, for example, Credé et al. [22] have shown in a meta-analytic review that there is a correlation between class attendance and class grades and that class attendance is a better predictor than other known predictors of performance. Bennett and Yalams [23] also report that attendance and participation in class are positively and significantly related with performance, with attendance achieving better results than participation. Whether class attendance can be an indicative predictor for student performance was also tested and confirmed in a study by Stewart et al. [24]. In an undergraduate statistics course Latif and Miles [25] also explored the impact of class attendance on course outcomes and found that the impact was a significant and positive one after controlling for factors related to ability and effort. Louis et al. [26] also conducted studies to investigate whether class attendance in face-to-face classes is significantly and positively related to the students' performance and found that in undergraduate psychology courses this was indeed the case. Thus, being present in a course can be seen as an important predictor for study success.

What has been confirmed in face-to-face classes has also been observed in online and distance education as shown by Korkofingas and Macri [27]. The researchers revealed that the more time students spent online and are 'present' on the course's website the better their assessed performance was. Macfadyen and Dawson [28] on the other hand found that time online only weakly correlated with course outcomes while the contribution to discussion forums received significant results. While the recent findings of Strang [29] suggest that course logins are significant in predicting student online learning outcomes, Tempelaar et al. [30] on the other hand investigated the predictive power of learning dispositions, formative assessment results and log data, and showed that computer-supported formative assessment during a course was a better predictor than the collected LMS data. The effects of different types of behaviour and activities in online classes are thus still under discussion and are most likely strongly context-dependent.

As part of this discussion about effectiveness and contextuality there are some recent studies that try to go further and investigate the impact of learning analytics dashboards on aspects such as motivation and individual goal attainment of learners. Lonn et al. [31] investigated the effect of a learning analytics dashboard on the motivation of students that are in danger of failing. Their findings show that student goal perceptions and formative performance results need to be carefully considered in the application of learning analytics dashboards as the results can significantly affect the interpretation of the students' own academic chances. Beheshitha et al. [32] also focused on investigating the effect of visualisations on different factors of learning. They showed that depending on the data used for the visualisations, positive as well as negative results can be found for the impact of visualisations on the learning progress and suggest a structured methodology for those types of studies. Khan and Pardo [33] also identified the need to present different kinds of dashboards and widgets depending on the information needs of the learners as well as the learning activity to make them effective.

All three studies thus emphasise the need to carefully embed dashboards into instructional designs and to try to take the learners' personal preferences into account. A good learning analytics system thus seems to need either good moderation or different analytics visualisations depending on the learners' different goals and performances to increase their motivation. 


\subsection{Our Approach}

Taking all this into account, we have designed a widget based on learning analytics within the learning environment of the European Virtual Seminar on Sustainable Development (EVS), a joint course of about ten European universities that is coordinated by the Open University of the Netherlands. The widget provides several types of feedback based on data automatically collected in the EVS platform, visualised in radar charts and bar charts. Its aim is to make students aware of their own platform activity relative to that of the group and of differences in activity between the group members. The widget also aims at fostering reflection about how their behaviour influences the their future status, i.e. in relation to their position within the group and in relation to their course outcome.

To achieve these goals, however, and before offering the learning analytics widget in a live run of the course, we report in this article the results of a formative data study measuring whether the widget indicators validly reflect the individual students' grades given by the tutors, i.e. the purpose of this study is to find out whether and if so how the different widget indicators relate to the grades given by the tutors. Thus, before deploying the widget in a live run of the course, we tested whether the information visualised in the widget is indeed valid and reliable in terms of outcome reflection and how it can be interpreted. We thus wanted to know: How do the widget indicators correlate with the tutor gradings and can they validly reflect them? To answer this question, we computed the widget indicator scores with data from four previous runs of EVS and analysed how the tutor gradings of individual students in those years correlated with the scores generated for the widget indicators with the aim to establish the reflective, i.e. predictive, validity of the widget indicator scores for the students' grades. The analysis was done for the whole run of the course as well as for individual months in order to obtain results for different levels of granularity and for different points in time.

We analysed the data with the following research questions in mind:

(RQ1) Do the widget indicator scores correlate with the tutor gradings of individual students?

(RQ2) Are the scores of some widget indicators better predictors for the students' individual grades than others?

(RQ3) Do certain points in time produce indicator scores that are better grade predictors than others?

Based on these questions the following hypotheses were thus tested in the experiment:

(H1) There is a significant positive correlation between tutor gradings of individual students and the widget indicator scores.

(H2) The scores of the widget indicator 'presence' are better predictors for the students' individual grades than those of the widget indicators 'initiative' and 'responsiveness'.

(H3) The widget indicator scores produced in the second half of the course are better predictors than those of the first half.
The next section describes the course as well as the widget in more detail and elaborates on our method of a two-step analysis, i.e. correlation analysis to uncover potential relationships between tutor grades and widget indicator scores followed by structural equation modelling to determine the strength of the relationships as well as the fit on the data. After the presentation of the analysis results, the discussion section sets the results in relation to the hypotheses and addresses some limitations of our study. The final section concludes the article.

\section{Method}

\subsection{Participants and Materials}

\subsubsection{The EVS Course}

The European Virtual Seminar on Sustainable Development $(E V S)^{2}$ is a joint, web-based Master-level course offered by a partnership of about ten universities (regular as well as distance) from across Europe. The aim of EVS is to foster competences for sustainable development through collaborative learning in virtual, international, multidisciplinary student teams. Here, we provide a brief description of the characteristics of EVS, relevant to the study presented in this article. An extensive description of EVS is provided in [34].

Each year, EVS runs from 1 November till 1 April of the next year. During these five months, students from different countries and disciplines work together in teams of four to seven persons on sustainability issues, such as waste management, nature conservation, and climate adaptation. The students from the regular universities are usually between 20 and 25 years of age while the students from the distance universities are usually between 30 and 50 years old. Each run, there are about nine teams in EVS, working on different topics. Coached by a tutor and guided by an issue expert, the teams conduct a small-scale research project, mostly using secondary data that can be accessed through the internet.

The final grade of the students consists of a combination of grades for several aspects of the course. $50 \%$ of the final grade is based on the grade for the quality of the research report a team produces, assessed by the expert; $20 \%$ of the final grade is based on the grade for the quality of the group collaboration process, assessed by the tutor; and $30 \%$ of the final grade is based on a grade for the individual student's contribution to this collaboration process, also assessed by the tutor. The individual student's contribution grade, i.e. the 'individual-overall' grade (T4 in Table 1) is determined by taking the average of the three sub-grades 'T1 planning \& progress', 'T2 contribution to team', and 'T3 support'. Each of them covers a range of aspects in the students' contributions (see Table 1).

The grades for the report and for the group collaboration process are strongly correlated, and the more team members have low grades for their individual contribution, the lower the grade for the group collaboration will be [34]. A high level of participation of individual team members is thus important for a good collaboration process in the team, which in turn translates in high-quality group products.

2. http://www.ou.nl/evs 
TABLE 1

Aspects of the individual grades (tutor-based) for students within EVS

\begin{tabular}{ll}
\hline \hline grade & aspects covered by grade \\
\hline \hline T1 planning \& progress & $\begin{array}{l}\text { planning a realistic own workload } \\
\text { dealing with deadlines and agreements } \\
\text { flexibility in making appointments/agreements/planning } \\
\text { ability to change roles and responsibilities }\end{array}$ \\
\hline T2 contribution to team & $\begin{array}{l}\text { dealing with feedback from the group } \\
\text { taking initiative, helping the group to progress } \\
\text { productivity and quality of contributions }\end{array}$ \\
\hline T3 support & $\begin{array}{l}\text { being supportive (offering support and help others) } \\
\text { encourage the learning of the other members } \\
\text { giving feedback / reviewing contributions of others }\end{array}$ \\
\hline T4 individual-overall & overall grade (average of the three sub-grades) \\
\hline \hline
\end{tabular}

In our experience, a common cause of poor group performance in EVS are large differences in individual contribution between the team members, which often results in gradual demotivation of the more active students or an increasing frequency of open conflicts. Visualisation of individual students' activity could thus help to detect and openly discuss such differences at an early stage, which may prevent conflicts and have a positive effect on team performance and group atmosphere.

The Elgg-based platform ${ }^{3}$ used by EVS since 2011 automatically collects and generates data on student activity, which can be used to feed a learning analytics widget that gives the students visual feedback on their own activity and how this compares to their team members and team average. The next section provides a description of our widget.

\subsubsection{The Widget}

While this section describes the widget we developed and its indicators and functionalities, it is important to emphasise that for the current study we did not test the widget

3. Elgg is a leading open source social networking engine, see: https://elgg.org/

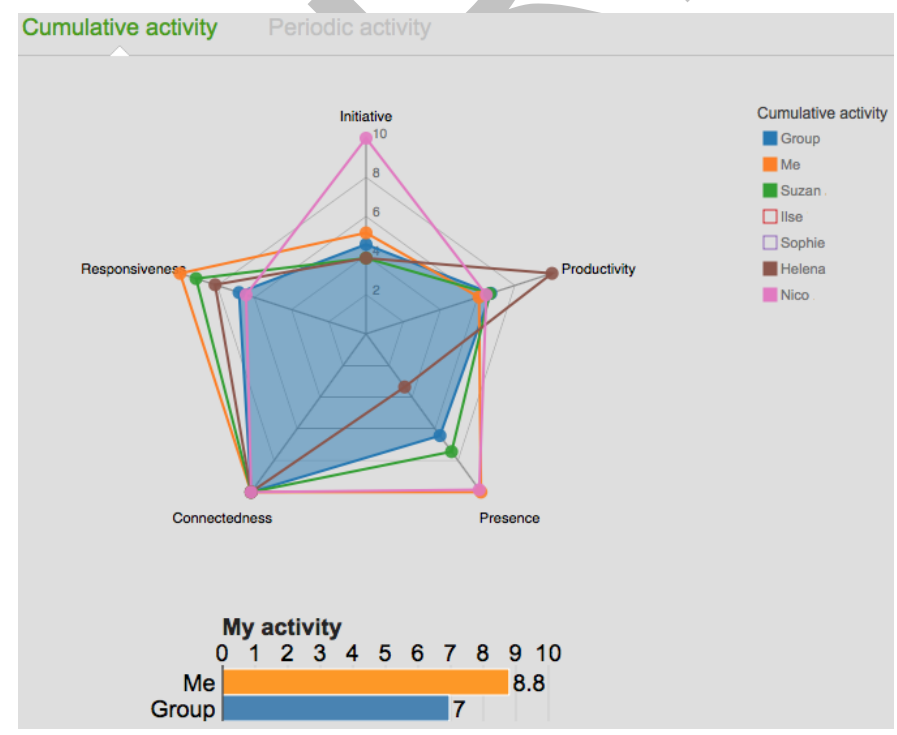

Fig. 1. Cumulative view of the widget.
TABLE 2

Calculation of the five widget indicator scores

\begin{tabular}{lll}
\hline \hline & widget indicator & calculation of the widget indicator scores \\
\hline \hline W1 & initiative & \# of posts (discussion, blog, files, pages) \\
W2 & responsiveness & \# of comments to posts (discussion, blog, files, pages) \\
W3 & presence & \# of page views (on EVS platform) \\
W4 & connectedness & \# of contacts made \\
W5 & productivity & (W1 initiative + W2 responsiveness) / W3 presence \\
\hline \hline
\end{tabular}

with real users in a live run, but rather tested the reflective and thus predictive validity of the widget indicators (see Table 2) with data gathered in previous course runs. Nevertheless, it is important to present the widget and its functionalities here to provide the reader with the idea behind the developed tool and how it can be applied.

The widget, available for download under GNU GPL version 2 [35], can be embedded within an Elgg environment as a plugin to make students aware of and reflect on their activity level within the environment relative to other group members and the group average. The widget contains information about the users' platform activities with two subsections, i.e. the cumulative view and the periodic view.

Platform activity is expressed in five widget indicators: 'W1 initiative', 'W2 responsiveness', 'W3 presence', 'W4 connectedness', and 'W5 productivity'. The widget indicator scores are automatically calculated from activity data recorded by the EVS platform (see Table 2). The students' activity is visualised in a radar chart, with five axes for the five widget indicators. When hovering with the mouse over the labels of the axes, the definition of the widget indicator is displayed. When pointing with the cursor at the dots in the chart, the corresponding widget indicator score is displayed.

The 'Cumulative activity' radar chart (see Figure 1) presents the widget indicator scores for the whole run of EVS, i.e. from the beginning of the course until the current date. In this and all other charts, orange is used for a user's own scores ('Me'), and blue for the group average ('Group'). The scores in the radar chart are scaled from 0 to 10. For each widget indicator, the group member with the highest activity gets a score of 10 and the scores of the other

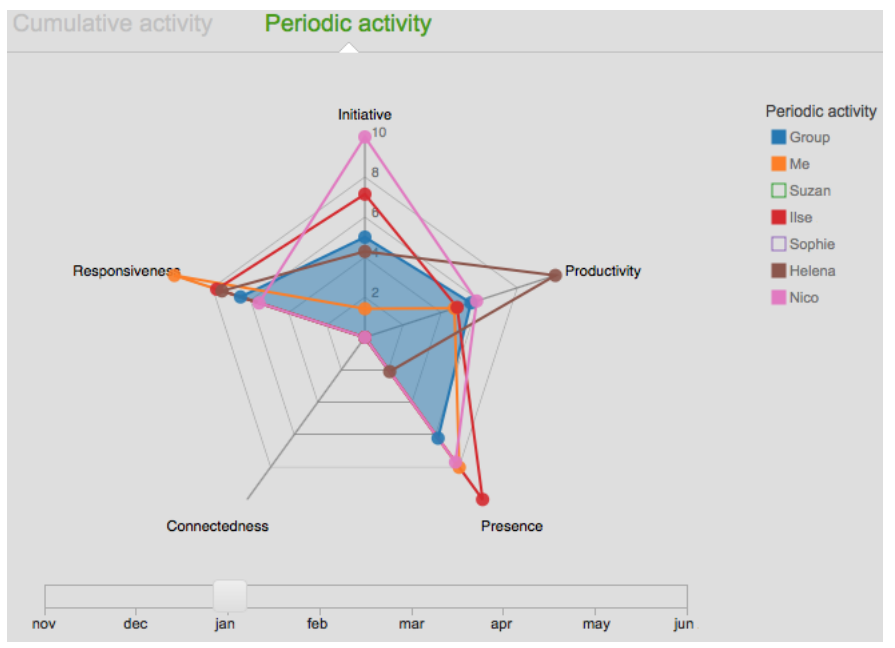

Fig. 2. Periodic view of the widget. 
members are scaled accordingly. The colour coding also applies to the 'My activity' bar chart. The orange bar shows a user's average activity, i.e. average of the widget indicators 'W1 initiative', 'W2 responsiveness', 'W3 presence' and 'W4 connectedness', compared to the average of the entire group (blue bar). The 'Periodic activity' radar chart presents the widget indicator scores per month (see Figure 2). Users can choose the specific month with a slider below the chart.

In order to facilitate group performance by enabling coand self-regulation processes, the widget indicator scores of the individual members of a group are visualised. As explained by Drachsler and Greller [36] in their article about privacy and ethics in learning analytics, this information can be classified as 'privacy sensitive' information that needs to be handled according to the DELICATE checklist as not all students of a group might agree to share this 'privacysensitive' information within the group. To deal with these privacy and ethical issues, the process suggested by the DELICATE checklist was followed. When the widget will be used in a live run of an EVS course, a widget manual explaining the intentions behind the learning analytics widget, making clear what data is being collected, how it is presented in the widget, and what students can do to protect their privacy will be provided to all EVS users.

Catering to this last point, a Reciprocal Privacy Model (RPM) is implemented into the widget. The RPM enables students to decide how they would like to share their activity data. A target student can only see the individual performance of other students in his team if he also agrees to share his own data with the rest of the team. If a student disagrees with sharing his data, he will only see his own performance in comparison to the group average value in the radar chart of the widget. When he agrees to sharing his own activity data, he will also see the data shared by other members of the team. The RPM model is a very innovative approach that empowers the students to decide with whom and on which level they want to share their data.

\subsection{Procedure}

As explained, data from the previous four runs of EVS were used in order to obtain those years' widget indicator scores for widget indicators 'W1 initiative', 'W2 responsiveness' and 'W3 presence' ${ }^{4}$. The widget indicator scores for 'W4 connectedness' and 'W5 productivity' were not included in the analysis. 'W4 connectedness" was excluded as it turned out that the number of contacts students made (similar to 'friending' in informal social networks) varied strongly and irregularly between EVS runs and teams within the same run. The course manual advised students to make other students contacts, in particular their team members, as this allows them to receive notifications about their platform activities. However, it seems that the number of contacts students in EVS made primarily depended on whether or not the tutor of a group emphasised the need of this feature, rather than the internal motivation of the students to improve communication. 'W5 productivity' was excluded as it represents a combination of three other widget indicators and is thus not an independent variable. Gender, age and

4. Unfortunately, the 'W3 presence' scores for the EVS run of 20112012 were not available. nationality of the students were not taken into account in the analysis. Table 3 shows the descriptive statistics of the three widget indicators for all years pooled for all months combined as well as all individual months.

In a first step, the scores of the three widget indicators (W1, W2, W3) for the four runs were correlated with the students' four individual grades (T1, T2, T3, T4) as given by their tutors. As the data from the widget indicators consist of count variables and thus have a Poisson distribution, Spearman's rank correlation was used, i.e. all widget scores as well as all grades were ranked with 1 being assigned to the highest ranking scores and grades and ties being assigned an average rank. Due to the ranking, differences in grading style between tutors as well as differences in units and scales were thus corrected for. Spearman's rank correlation coefficient was calculated to determine the strength of association between ranked grades and widget indicator scores as well as the significance level. The correlation coefficients were calculated for all runs pooled for the entire length of a run and for individual months.

In order to not only learn something about the strength of association but also about predictive relations between widget indicator scores and grades, more advanced statistical analysis on the data is necessary. For analyses such as structural equation modelling, however, the data needs to be normally distributed. With the data from the widget indicators having a Poisson distribution, this is thus theoretically not possible. However, if the collected count variable data are nearly normally distributed, i.e. if their mean value is far enough from 0 , such analyses can be done ${ }^{5}$. As this is the case for most of the means of the widget indicator data (see Table 3), we assumed them to be nearly normally distributed and thus, as the second step of our analysis, also conducted structural equation modelling between the three widget indicators (W1, W2, W3) and the students' four individual grades (T1, T2, T3, T4) on the basis of an entire run as well as the individual months for all years pooled.

\section{Results}

\subsection{Correlations}

The correlation calculations were conducted using IBM's SPSS Statistics 23. The results of Spearman's rank correlation for all runs pooled (see Table 4) show that when student activity is measured during the entire length of the course run, all four tutor-based grades (T1-T4) are significantly and positively correlated with all widget indicators (W1W3) except for the T1/W3 combination. For the widget indicators, the highest correlation coefficients are obtained for the indicator 'W2 responsiveness' and the lowest for the 'W3 presence' indicator.

This holds true for all grades. For the grade 'T1 planning \& progress' the correlation coefficient obtained with the 'W2 responsiveness' indicator is .338, for the grade 'T2 contribution to team' it is .415 and for the grade 'T3 support' it is .414. The 'T2 contribution to team'/'W2 responsiveness' combination is the highest scoring grade-widget indicator

5. The mean should be $>10$ to be far enough from 0 according to https://www.umass.edu/wsp/resources/poisson/ and https://www.umass.edu/wsp/resources/poisson/poisson1.html and https://www.umass.edu/wsp/resources/poisson/poisson2.html. 
TABLE 3

Descriptive statistics of the widget indicators ' $W 1$ initiative', 'W2 responsiveness' and ' $W 3$ presence': all runs pooled, activity measured over the entire length of a run as well as activity measured per month.

\begin{tabular}{|c|c|c|c|c|c|c|c|c|c|c|c|c|}
\hline & \multirow{2}{*}{$\begin{array}{r}\mathrm{N} \\
\text { Stat. }\end{array}$} & \multirow{2}{*}{$\begin{array}{c}\text { Range } \\
\text { Stat. }\end{array}$} & \multirow{2}{*}{$\begin{array}{l}\text { Min } \\
\text { Stat. }\end{array}$} & \multirow{2}{*}{$\begin{array}{l}\text { Max } \\
\text { Stat. }\end{array}$} & \multicolumn{2}{|c|}{ Mean } & \multirow{2}{*}{$\begin{array}{l}\text { Std. Dev. } \\
\text { Stat. }\end{array}$} & \multirow{2}{*}{$\begin{array}{r}\text { Variance } \\
\text { Stat. }\end{array}$} & \multicolumn{2}{|c|}{ Skewness } & \multicolumn{2}{|c|}{ Kurtosis } \\
\hline & & & & & Stat. & Std. Err. & & & Stat. & Std. Err. & Stat. & Std. Err. \\
\hline W1 all months & 172 & 124 & 0 & 124 & 17,30 & 1.323 & 17.346 & 300.888 & 3.182 & .185 & 15.507 & .368 \\
\hline W3 all months & 134 & 5239 & 240 & 5479 & 1291.88 & 85.539 & 990.186 & 980468.452 & 2.109 & .209 & 4.780 & .416 \\
\hline W1 month1 & 172 & 40 & 0 & 40 & 3.53 & .393 & 5.151 & 26.531 & 3.513 & .185 & 17.521 & .368 \\
\hline W2 month1 & 172 & 89 & 1 & 90 & 17.00 & .922 & 12.097 & 146.327 & 2.328 & .185 & 8.898 & .368 \\
\hline W1 month2 & 172 & 74 & 0 & 74 & 3.44 & .506 & 6.637 & 44.049 & 7.496 & .185 & 75.248 & .368 \\
\hline W2 month2 & 172 & 54 & 0 & 54 & 11.30 & .648 & 8.500 & 72.245 & 1.672 & .185 & 4.064 & .368 \\
\hline W3 month2 & 134 & 1392 & 21 & 1413 & 227.98 & 18.692 & 216.371 & 46816.443 & 2.514 & .209 & 8.909 & .416 \\
\hline W1 month3 & 172 & 15 & 0 & 15 & 2.03 & 196 & 2.574 & 6.625 & 2.118 & .185 & 5.776 & .368 \\
\hline W2 month3 & 172 & 37 & 0 & 37 & 7.93 & .469 & 6.153 & 37.855 & 1.750 & .185 & 4.819 & .368 \\
\hline W3 month3 & 134 & 1093 & 6 & 1099 & 177.86 & 13.640 & 157.898 & 24931.671 & 2.411 & .209 & 9.298 & .416 \\
\hline W2 month5 & 166 & 58 & 0 & 58 & 12.89 & .841 & 10.841 & 117.520 & 1.654 & .188 & 3.561 & .375 \\
\hline W3 month5 & 134 & 1216 & 18 & 1234 & 264.10 & 20.734 & 240.019 & 57609.186 & 1.919 & .209 & 4.195 & .416 \\
\hline
\end{tabular}

TABLE 4

Spearman correlation coefficients of the association between individual grades (tutor-based) and widget indicator scores (widget-based): all runs pooled, activity measured over the entire length of a run.

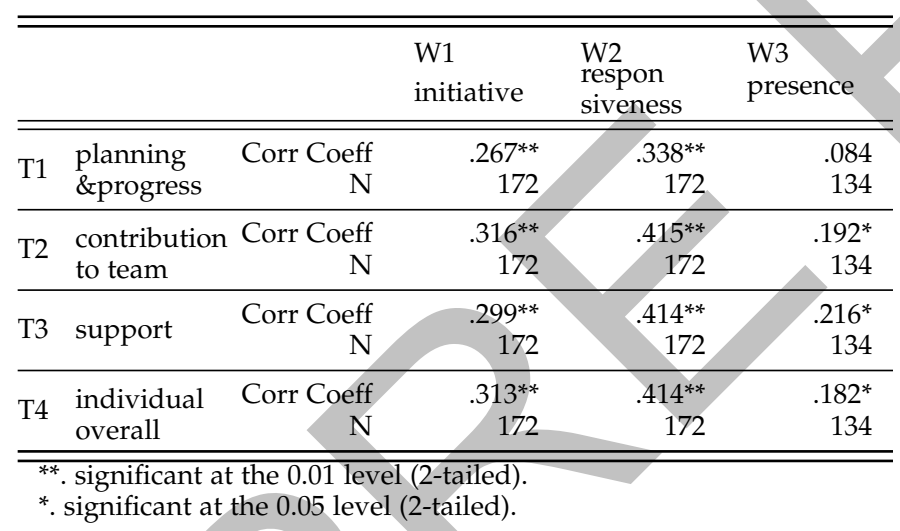

combination but with a correlation coefficient of .415 the 'T3 support'/'W2 responsiveness' combination as well as the 'T4 individual-overall'/'W2 responsiveness' combinations are almost as high.

When the Spearman rank correlation coefficients for all runs pooled are calculated per month instead of over the entire length of a run, there are again many grade-widget indicator combinations that are significantly positively correlated (see Table 5). All four grades correlate best with the 'W2 responsiveness' indicator in month1 or month2 (i.e. November and December). The 'W3 presence' indicator, again, has the lowest correlation coefficients. While the coefficients for the 'W2 responsiveness' indicator are almost all highest in month2, the 'W1 initiative' indicator has the highest correlation coefficients in month1. The 'W3 presence' indicator only has a few significant correlations.
The highest of these are received in month2. The grade 'T1 planning \& progress' never significantly correlates with the 'W3 presence' indicator. The lowest correlation coefficients for all three widget indicators are obtained in month 5 with only the 'W2 responsiveness' indicator obtaining significant correlations at all. The 'W3 presence' indicator score of month 5 even receives a negative correlation coefficient with the grade 'T1 planning \& progress', albeit an non-significant one.

Looking at the correlations from the perspective of the different grades, it shows that the 'T1 planning \& progress' grade correlates best with the 'W2 responsiveness' indicator in month1 (.363), and the 'T2 contribution to team' grade correlates best with the 'W2 responsiveness' indicator in month2 (.393), as do the 'T3 support' grade and the 'T4 individual-overall' grade (.399 and .403 respectively).

\subsection{Structural Equation Modelling}

Regression analyses using structural equation modelling were performed in Mplus 7. The regressions performed pertained to two situations: in the first one the three grades 'T1 planning \& progress', 'T2 contribution to team' and 'T3 support' functioned as the dependent variables, while in the second one grade 'T4 individual-overall' was the only dependent variable. This was done due to $\mathrm{T} 4$ being a combination of the other three grades. All calculations were done with all years pooled for the whole run of the course as well as for the individual months.

Different fit indices have been calculated for the different analyses: the Comparative Fit Index (CFI) [37], [38], the Tucker-Lewis Index (TLI), and the Root Mean Squared Error of Approximation (RMSEA) as well as the Standardised Root Mean Square Residual (SRMR) [39]. In order to have a moderate to good model fit these indices should satisfy 
TABLE 5

Spearman correlation coefficients of the association between individual grades (tutor-based) and widget indicator scores (widget-based): all runs pooled, activity measured per month.

\begin{tabular}{|c|c|c|c|c|c|c|c|c|c|c|c|c|c|c|c|c|c|}
\hline & & & ${ }_{\mathrm{m} 1}^{\mathrm{W}}$ & ${ }_{\mathrm{m} 2}^{\mathrm{i}} \mathrm{i}$ & i $t \underset{\text { m }}{\mathrm{i}} \mathrm{a}$ & $\begin{array}{l}\mathrm{t} \underset{\mathrm{i}}{\mathrm{m} 4} \\
\mathrm{~m}\end{array}$ & e m5 & $\begin{array}{l}\text { W2 } \\
\text { m1 }\end{array}$ & $r \underset{m 2}{r}$ e s p & $\begin{array}{l}\text { o } \mathrm{n} \mathrm{s} \text { i } \\
\mathrm{m} 3\end{array}$ & $\begin{array}{l}\mathrm{v} \text { e } \mathrm{n} \\
\mathrm{m} 4\end{array}$ & $\begin{array}{l}\mathrm{s} \mathrm{s} \\
\mathrm{m} 5\end{array}$ & $\begin{array}{l}\text { W3 } \\
\text { m1 }\end{array}$ & $\mathrm{p}_{\mathrm{m} 2}^{\mathrm{r}}$ & e $\underset{\mathrm{m} 3}{\mathrm{~s}} \mathrm{e}$ & $\begin{array}{l}\mathrm{n} \\
\mathrm{m} 4\end{array}$ & $\begin{array}{l}\mathrm{e} \\
\mathrm{m} 5\end{array}$ \\
\hline & planning & Corr Coeff & $.347^{* *}$ & $.252^{* *}$ & $.170^{*}$ & $.189 *$ & .032 & $.363^{* *}$ & $.327^{* *}$ & $.195^{* *}$ & $.272^{* *}$ & .138 & .074 & .161 & .067 & .093 & -.056 \\
\hline & \&progress & $\mathrm{N}$ & 172 & 172 & 172 & 168 & 172 & 172 & 172 & 172 & 172 & 166 & 134 & 134 & 134 & 134 & 134 \\
\hline \multirow{2}{*}{$\mathrm{T} 2$} & contribution & Corr Coeff & $.369^{* *}$ & $.324^{* *}$ & $.218^{* *}$ & $.224^{* *}$ & .050 & $.378^{* *}$ & $.393^{* *}$ & $.295^{* *}$ & $.353^{* *}$ & $.189^{*}$ & .159 & $.232^{* *}$ & .150 & $.193^{*}$ & .005 \\
\hline & to team & $\mathrm{N}$ & 172 & 172 & 172 & 168 & 172 & 172 & 172 & 172 & 172 & 166 & 134 & 134 & 134 & 134 & 134 \\
\hline \multirow{2}{*}{ T3 } & & Corr Coeff & $.361^{* *}$ & $.284^{* *}$ & $.205^{* *}$ & $.166^{*}$ & .064 & $.356^{* *}$ & $.399 * *$ & $.275^{* *}$ & $.330^{* *}$ & $.241^{* *}$ & .166 & $.227^{* * *}$ & $.179^{*}$ & $.195^{*}$ & .072 \\
\hline & support & $\mathrm{N}$ & 172 & 172 & 172 & 168 & 172 & 172 & 172 & 172 & 172 & 166 & 134 & 134 & 134 & 134 & 134 \\
\hline & individual & Corr Coeff & $.380^{* *}$ & $.306^{* *}$ & $.209^{* *}$ & $.207^{* *}$ & .046 & $.386^{* *}$ & $.403^{* *}$ & $.272^{* *}$ & $.338^{* *}$ & $.197^{*}$ & .151 & $.232^{* * *}$ & .145 & $.176^{*}$ & .011 \\
\hline & overall & $\mathrm{N}$ & 172 & 172 & 172 & 168 & 172 & 172 & 172 & 172 & 172 & 166 & 134 & 134 & 134 & 134 & 134 \\
\hline
\end{tabular}

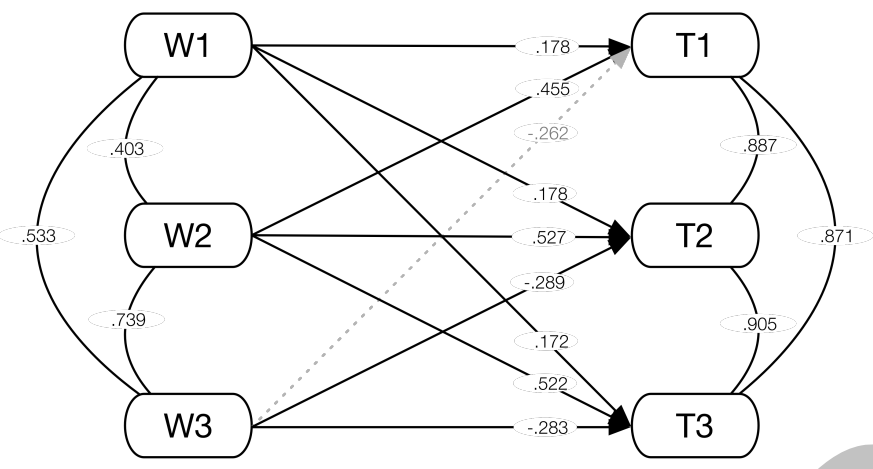

Fig. 3. Graph of the structural equation modelling with standardised path coefficients ( $\beta$ weights) for grades T1, T2 and T3 and all widget indicator scores: all runs pooled, activity measured for the entire length of the run.

the following conditions: CFI $\geq .90$; TLI $\geq .90$; RMSEA $\leq .80$; and SRMR $\leq .08$. The model we entered was fully saturated, i.e. all relationships were considered, and all CFIs and TLIs were therefore equal to 1.0 and all RMSEAs and SRMRs were equal to 0.0 .

Figures 3 and 4 depict the results of the two regression analysis situations mentioned above for the entire length of the run. ${ }^{6}$ Conducting the structural equation modelling for the entire length of the run and the three grades 'T1 planning \& progress', 'T2 contribution to team' and 'T3 support' shows that except for the 'T1 planning \& progress'/'W3 presence' combination all three widget indicator scores can be used as predictors for the grades (see Table 6). The strongest predictive relations are achieved with the 'W2 responsiveness' indicator (all of them are above .455). The relations between the 'W3 presence' indicator and the grades are negative but stronger than the positive relations between the 'W1 initiative' indicator and the grades (the former are around -.285 while the latter are around .175).

Conducting the structural equation modelling for grade 'T4 individual-overall' results in very similar standardised path coefficients ( $\beta$ weights). The strongest predictor for the grade is the ' $\mathrm{W} 2$ responsiveness' indicator while ' $\mathrm{W} 3$ presence' shows a negative predictive relation. All three widget indicators obtain significant relations.

6. For reasons of enhanced readability / reading flow, only the results for the entire length of the run are depicted graphically.

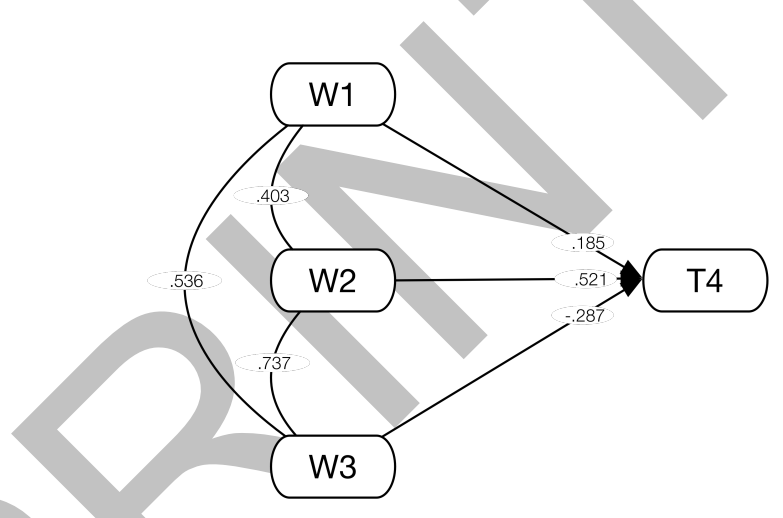

Fig. 4. Graph of the structural equation modelling with standardised path coefficients ( $\beta$ weights) for grade T4 and all widget indicator scores: all runs pooled, activity measured for the entire length of the run.

TABLE 6

Standardised path coefficients $(\beta)$ and their significances from the structural equation modelling with the individual grades (tutor-based) as dependent and the widget indicator scores (widget-based) as independent variables: all runs pooled, activity measured over the entire length of a run

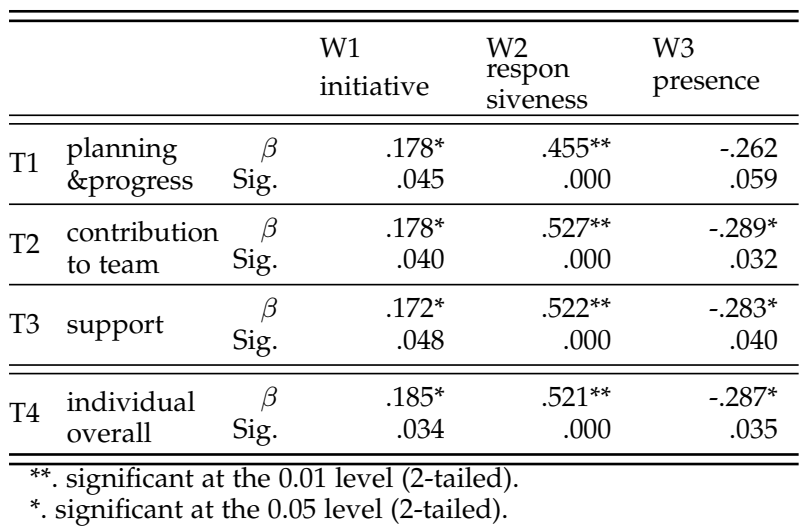

Looking at the standardised path coefficients of the structural equation modelling for the different months (see Table 7) shows that the 'W2 responsiveness' receives a positive and significant relation with all grades in all months, i.e. it can be used as a predictor for the three grades. The 'W3 presence' indicator always obtains a negative relation with the grades which is significant only in month1 (.333). For indicator ' $W 1$ initiative' the relations are positive 
TABLE 7

Standardised path coefficients $(\beta)$ and their significances from the structural equation modelling with the individual grades (tutor-based) as dependent and the widget indicator scores (widget-based) as independent variables: all runs pooled, activity measured per month

\begin{tabular}{|c|c|c|c|c|c|c|c|c|c|c|c|c|c|c|c|c|c|}
\hline & & & ${ }_{W 1}^{m}$ & $\begin{array}{l}\mathrm{O} \mathrm{n} \mathrm{h} \\
\mathrm{W} 2\end{array}$ & 1 W3 & ${ }_{W 1}^{m}$ & $\begin{array}{l}\mathrm{o} n \mathrm{t} \\
\mathrm{W} 2\end{array}$ & $\begin{array}{l}2 \\
\text { W3 }\end{array}$ & ${ }_{\mathrm{W} 1}^{\mathrm{m}}$ & $\begin{array}{l}\mathrm{o} \mathrm{n} \mathrm{t} h \\
\mathrm{~W} 2\end{array}$ & $\begin{array}{l}3 \\
\text { W3 }\end{array}$ & ${ }_{W 1}^{m}$ & $\begin{array}{l}\mathrm{o} \mathrm{n} \mathrm{t} \\
\mathrm{W} 2\end{array}$ & $\begin{array}{l}4 \\
\text { W3 }\end{array}$ & $\underset{W 1}{m}$ & ${ }_{\mathrm{W} 2}^{\mathrm{n} t \mathrm{~h}}$ & $\begin{array}{l}5 \\
\text { W3 }\end{array}$ \\
\hline & planning & $\beta$ & $.314^{* *}$ & $.434^{* *}$ & $-.333^{*}$ & .050 & $.385^{* *}$ & -.149 & $.180^{*}$ & $.247^{*}$ & -.113 & .117 & $.313^{* *}$ & -.145 & -.014 & $.249^{*}$ & -.060 \\
\hline & \&progress & Sig. & .000 & .000 & .023 & .630 & .000 & .326 & .025 & .018 & .368 & .227 & .004 & .318 & .877 & .040 & .661 \\
\hline \multirow{2}{*}{$\mathrm{T} 2$} & contribution & $\beta$ & $.295^{* *}$ & $.372^{* *}$ & -.223 & .033 & $.423^{* *}$ & -.136 & $.185^{*}$ & $.338^{* *}$ & -.142 & .140 & $.382^{* *}$ & -.186 & -.032 & $.355^{* *}$ & -.140 \\
\hline & to team & Sig. & .000 & .002 & .127 & .746 & .000 & .359 & .018 & .001 & .241 & .146 & .000 & .187 & .724 & .003 & .295 \\
\hline \multirow{2}{*}{ T3 } & \multirow{2}{*}{ support } & $\beta$ & $.297^{* *}$ & $.371^{* *}$ & -.235 & .024 & $.424^{* *}$ & -.140 & $.163^{*}$ & $.300^{* *}$ & -.097 & .126 & $.374^{* *}$ & -.173 & -.020 & $.357^{* *}$ & -.115 \\
\hline & & Sig. & .001 & .002 & .114 & .812 & .000 & .349 & .040 & .003 & .433 & .188 & .000 & .227 & .821 & .002 & .395 \\
\hline \multirow{2}{*}{$\mathrm{T} 4$} & individual & $\beta$ & $.306^{* *}$ & $.398^{* *}$ & -.254 & .036 & $.425^{* *}$ & -.141 & $.185^{*}$ & $.309^{* *}$ & -.123 & .134 & $.371^{* *}$ & -.175 & -.020 & $.339^{* *}$ & -.114 \\
\hline & overall & Sig. & .000 & .001 & .088 & .724 & .000 & .345 & .019 & .002 & .320 & .165 & .000 & .219 & .826 & .004 & .399 \\
\hline
\end{tabular}

**. significant at the 0.01 level (2-tailed). ${ }^{*}$. significant at the 0.05 level (2-tailed).

and significant in month1 and month3 only. In month5 all grade/'W1 initiative' combinations have a negative relation but are not significant.

From the perspective of the grades, the highest positive predictive relation for 'T1 planning \& progress' is achieved with the 'W2 responsiveness' score in month1 (.434) while the strongest negative predictive relation is received with the 'W3 presence' score in month1 (-.333). The best positive predictive relation for grades 'T2 contribution to team', 'T3 support' and 'T4 individual-overall' is obtained with the widget indicator score ' $\mathrm{W} 2$ responsiveness' in month2 (.423 and .424 and .425). There are no significant negative predictive relations for these grades in the individual months.

\section{Discussion}

When all runs are pooled and the activity is calculated over the whole run of the course, the Spearman correlation results show that the scores of all three widget indicators significantly and positively correlate with all four grades

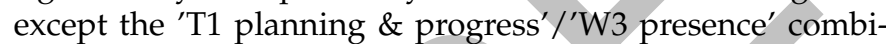
nation whose relation is not significant. Hypothesis 1 (There is a significant positive correlation between tutor gradings of individual students and the widget indicator scores) can thus be accepted.

Adding to this, the results of the structural equation modelling shows that there is indeed a positive and significant predictive relation between the widget indicators 'W1 initiative' and 'W2 responsiveness' and all four grades while the widget indicator 'W3 presence' is in a significant but negative relation with the grades 'T2 contribution to team', 'T3 support' and 'T4 individual-overall', i.e. the widget indicators in those cases can be seen as predictors for the grades. The individual grades of the students as given by the tutors are mostly defined in qualitative terms (see Table 1). However, the analysis results between the purely quantitative widget indicator scores and these individual grades suggests that posting more while having lower presence scores tends to lead to better course grades, i.e. the more productive students (see our definition of the 'W5 productivity' indicator in Table 2) seem to be the better performers.

In particular, scores of the 'W2 responsiveness' indicator, i.e. the number of response posts made on the platform, correlate well with the different individual grades. This holds true for the calculations of the whole run as well as for the individual months. This suggests that it provides a reliable indication of students' individual performance. As the correlation between the scores of the widget indicator 'W3 presence' and the four grades tends to be lowest (but still significant) for the whole run as well as the individual months and as - except for the T1 / W3 combination - the 'W3 presence' indicator scores have no significant predictive relation with any of the grades, Hypothesis 2 (The scores of the widget indicator 'presence' are better predictors for the students' individual grades than those of the widget indicators 'initiative' and 'responsiveness'), is rejected.

This is interesting as a number of related works reported that class attendance or time online can be used as predictors for the course outcome. Also, one would intuitively assume that those students that are most interested in and motivated for the course are also those that show a high presence on the platform and thus receive the better grades. However, this does not seem to be the case here. The 'W3 presence' indicator scores therefore are not a very good a predictor for the students' individual grades. Our results thus correspond with those from Macfadyen and Dawson [28] who reported that contribution to discussions, i.e. posting something, received better correlation results with students' outcome than time online.

The good positive and significant Spearman correlation results as well as the positive and significant regression analysis results between the score of the widget indicator 'W2 responsiveness' and the individual grades especially in month2 could be explained by the observation that in the first months of the course, the students almost exclusively use the EVS platform, whereas after these months the students increasingly move to other means of communication, outside the EVS platform, notably Skype and Google Docs. As a consequence, a large part of the students' activity in these later months is not measured by the learning analytics widget. Based on the widget data alone, hypothesis 3 (The widget indicator scores produced in the second half of the course are better predictors than those of the first half) thus has to be rejected.

Again, this finding is interesting as we had originally thought that the last few months of the course would render better results than the first few as the most part of the 
group work in EVS is done towards the end of the course. The change to other means of communication over the time span of an EVS run, however, seems to have more impact than foreseen. The increased use of these other tools in the later months does, however, not necessarily mean that the students made fewer posts on the EVS platform (overall, the number of initiative posts increased towards the end, while the number of response posts decreased; presence also slightly decreased towards the end). It does, however, mean that there was a relative shift, i.e. the share of communication and collaboration decreased relative to the share outside the platform, and that there was a qualitative shift, i.e. the platform was still used for communication but much less for collaboration on joint products. The expected increase of activity thus did happen but not on the EVS platform and could thus not be captured by the widget.

Pertaining to the discussion about the effectiveness of learning analytics visualisations, our study contributes to it as we provide evidences for the effectiveness of dashboards for reflection and awareness of pure online collaborative learning processes. We investigated the predictive power of the indicators from our widget and were able to show that the final grades and widget indicator scores are significantly and positively correlated. This overall positive result provides a useful empirical basis for the development of instructional designs and activities within the EVS online course. As the EVS students do not meet face-to-face, we are confident that the widget, once it is implemented in a live run of the course, will support reflection and awareness of the collaborative learning processes, will provide valuable feedback to the learners on different activities of collaborative learning, and will contribute to an adjustment of the learning design of the course.

There are several aspects that have to be kept in mind when looking at the results of our analyses. First of all, as mentioned earlier, analysing distal data such as activity logs from a learning environment can never be used as a one-toone replacement for proximal data such as questionnaires or interviews. However, we support the view that the use of learning analytics can contribute to and enrich reflection and awareness processes for learners as well as teachers especially due to its non-disruptiveness and its taking into account of the full student cohort at the same time.

Another limitation of our study is that although we do look at behavioural data, we do not examine learning as a process itself. Neither do we explore whether any learning actually took place (for the purposes of our study we assume that a student's grade is an indicator of knowledge level) nor do we actually observe learning where and how it takes place, e.g. in the form of brain activity and modifications. Bio-psychological and educational neuroscience research is of huge importance for discovering the phenomenon of learning. On many levels, however, the brain and its ways of working are still a mystery [40], [41]. And although the recent year has seen learning analytics researchers contributing to this field by combining log data with data from biophysical sensors (e.g. [42]), addressing and taking into account these issues in the current paper would have been out of the scope of our study.

One of the biggest risks associated with this type of awareness and reflection support widget, or better, with this type of visualised information as we describe here is that students will use it 'strategically', e.g. by posting many short, largely irrelevant messages to improve their scores. Beheshitha et al. [32] report that showing students the top contributors of their course often resulted in more postings but not necessarily in ones with higher quality. As we did not use the widget in a live run of a course for this study, we did not have to take this risk into account yet. However, once the widget will be used, the best way to deal with such risks is to properly embed it into the instructional design of the course and to explain its aim and function to students and tutors. This might help to overcome issues like students 'playing the system' and tutors only using the widget indicators scores for grading. In addition, it may be useful to introduce a weighted form of scoring in the widget, e.g. by taking the length of posted comments into account, and to control for achievement goal orientations [31], [32].

Relating to the usage of the widget in a live run of the course, it will also be interesting to observe if and how the students will make use of the privacy option offered by the reciprocal privacy model implemented into the widget. Theoretically, if many or even all students within a group choose not to share their data, the widget's intention to support awareness and reflection of collaborative learning processes would be seriously interfered with or even prevented. A further risk is thus that by providing the students with privacy mechanisms, the likelihood of the widget being able to be the supportive tool it is meant to be decreases.

\section{CONCLUSION}

This paper presented a formative study about the reflective and thus predictive power of widget indicators of a learning analytics-based awareness widget towards students' grades. The results of our analysis show that the grades and widget scores are indeed significantly and positively correlated, with some widget indicators being valid reflectors, i.e. predictors, of the grades. On the basis of the results presented and discussed above, we suggest several guidelines concerning the interpretation of this learning analytics widget's visualisations in a live run of the course.

The scores of the widget indicator 'W3 presence' are not to be seen as a valid reflector for the final tutor-based grades of an individual student as they tend to have non-significant and negative predictive relations with all grades. They can, however, be useful to make students within a team aware of their group's dynamics.

The 'W2 responsiveness' indicator scores provide a good indication of an individual student's contribution to the group work and can thus be used as a basis for group reflection. Due to the significant and positive correlations and predictive relations of this widget indicator with all grades in the first few months, it can be used as a reflector for the students' final individual grades, under the condition of unchanged behaviour.

Taking the results from this analysis into account, the learning analytics widget is being integrated into the course platform for tutors and students in future live runs of EVS. Its impact on group awareness processes will be analysed with quantitative and qualitative measures such as the evaluation framework for learning analytics [43] and faceto-face experts workshops. 


\section{REFERENCES}

[1] K. Kreijns, P. A. Kirschner, and W. Jochems, "Identifying the pitfalls for social interaction in computer-supported collaborative learning environments: A review of the research," Computers in Human Behavior, vol. 19, no. 3, pp. 335-353, 2003.

[2] K. Kreijns, F. Van Acker, M. Vermeulen, and H. van Buuren, "Community of inquiry: Social presence revisited," E-Learning and Digital Media [Special Issue: Inquiry into 'Communities of Inquiry': Knowledge, Communication, Presence, Community, vol. 11, no. 1, pp. 5-19, 2014.

[3] P. Kirschner, K. Kreijns, C. Phielix, and J. Fransen, "Awareness of cognitive and social behaviour in a cscl environment," Journal of Computer Assisted Learning, vol. 31, no. 1, pp. 59-77, 2015.

[4] C. Phielix, F. J. Prins, P. A. Kirschner, G. Erkens, and J. Jaspers, "Group awareness of social and cognitive performance in a CSCL environment: Effects of a peer feedback and reflection tool," Computers in Human Behavior, vol. 27, no. 3, pp. 1087-1102, 2011.

[5] M. Fishbein and I. Ajzen, Predicting and Changing Behavior: The reasoned action approach. New York, NY, USA: Psychology Press, 2010.

[6] P. Long and G. Siemens, "Penetrating the Fog: Analytics in Learning and Education," EDUCAUSE Review, vol. 46, no. 5, pp. 30-40, 2011.

[7] D. Gašević, S. Dawson, N. Mirriahi, and P. Long, "Learning analytics - a growing field and community engagement," Journal of Learning Analytics, vol. 2, no. 1, pp. 1-6, 2015.

[8] D. Gašević, S. Dawson, and G. Siemens, "Let's not forget: Learning analytics are about learning," TechTrends, vol. 59, no. 1, pp. 64-71, 2014.

[9] W. Greller and H. Drachsler, "Translating Learning into Numbers: A Generic Framework for Learning Analytics," Educational Technology \& Society, vol. 37, no. 3, pp. 42-57, 2012.

[10] R. Ferguson, "Learning analytics don't just measure students' progress - They can shape it," theguardian.com, 2014. [Online] Available: http://gu.com/p/3np4c/sbl

[11] J. Hattie and H. Timperley, "The Power of Feedback," Review of Educational Research, vol. 77, no. 1, pp. 81-112, 2007.

[12] E. H. Mory, "Feedback Research Revisited," in Handbook of Research on Educational Communications and Technology, D. H. Jonassen, Ed. Mahwah, NJ, US: Lawrence Erlbaum Associates, 2004, pp. 745783.

[13] M. R. Endsley, "Toward a Theory of Situation Awareness in Dynamic Systems," Human Factors, vol. 37, pp. 32-64, 1995.

[14] _ " "Theoretical underpinnings of situation awareness: a critical review," in Situation Awareness Analysis and Measurement, M. R. Endsley and D. J. Garland, Eds. Mahwah, NJ, USA: Lawrence Erlbaum Associates, 2000.

[15] D. Schön, The reflective practitioner: How professionals think in action. London, UK: Temple Smith, 1983.

[16] G. Bolton, Reflective practice: Writing \& professional development, 3rd ed. London, UK: Sage, 2010.

[17] K. Verbert, E. Duval, J. Klerkx, S. Govaerts, and J. Santos, "Learning Analytics Dashboard Applications," American Behavioral Scientist, vol. 57, no. 10, pp. 1500-1509, 2013.

[18] D. Butler and P. Winne, "Feedback and self-regulated learning: a theoretical synthesis," Review of Educational Research, vol. 65, no. 3, pp. 245-281, 1995.

[19] P. H. Winne, "Inherent Details in Self-Regulated Learning," Educational Psychologist, vol. 30, no. 4, pp. 173-187, 1995.

[20] B. J. Zimmerman, "Self-Regulation Involves More Than Metacognition: A Social Cognitive Perspective," Educational Psychologist, vol. 30, no. 4, pp. 217-221, 1995.

[21] P. H. Winne, "How Software Technologies Can Improve Research on Learning and Bolster School Reform," Educational Psychologist, vol. 41, no. 1, pp. 5-17, 2006.

[22] M. Credé, S. G. Roch, and U. M. Kieszczynka, "Class Attendance in College: A Meta-Analytic Review of the Relationship of Class Attendance With Grades and Student Characteristics," Review of Educational Research, vol. 80, no. 2, pp. 272-295, 2010.

[23] T. Bennett and S. Yalams, "Correlates of students' attendance to class, participation and performances in engineering modules," in Global Engineering Education Conference (EDUCON), 2013 IEEE, 2013, pp. 947-951.

[24] M. Stewart, T. Stott, and A.-M. Nuttall, "Student Engagement Patterns over the Duration of Level 1 and Level 3 Geography Modules: Influences on Student Attendance, Performance and
Use of Online resources," Journal of Geography in Higher Education, vol. 35, no. 1, pp. 47-65, 2011.

[25] E. Latif and S. Miles, "Class Attendance and Academic Performance: A Panel Data Analysis," Economic Papers, vol. 32, no. 4, pp. 470-476, 2013.

[26] W. R. Louis, B. Bastian, B. McKimmie, and A. J. Lee, "Teaching psychology in Australia: Does class attendance matter for performance," Australian Journal of Psychology, vol. 68, pp. 47-51, 2016.

[27] C. Korkofingas and J. Macri, "Does Time Spent Online have an Influence on Student Performance? Evidence for a Large Business Studies Class," Journal of University Teaching $\mathcal{E}$ Learning Practice, vol. 10, no. 2, 2013. [Online]. Available: http://ro.uow.edu.au/jutlp/vol10/iss2/2

[28] L. Macfadyen and S. Dawson, "Mining LMS data to develop an "early warning system" for educators: A proof of concept," Computers \& Education, vol. 54, pp. 588-599, 2010.

[29] K. D. Strang, "Beyond engagement analytics: which online mixeddata factors predict student learning outcomes?" Education and Information Technologies, pp. 1-21, 2016

[30] D. T. Tempelaar, B. Rienties, and B. Giesbers, "In search for the most informative data for feedback generation: Learning analytics in a data-rich context," Computers in Human Behavior, vol. 47, pp. 157-167, 2015.

[31] S. Lonn, S. Aguilar, and S. Teasley, "Investigating student motivation in the context of a learning analytics intervention during a summer bridge program," Computers in Human Behavior, vol. 47, pp. 90-97, 2015.

[32] S. Beheshitha, M. Hatala, D. Gasevic, and S. Joksimovic, "The role of achievement goal orientations when studying effect of learning analytics visualizations," in Proceedings of the Sixth International Conference on Learning Analytics \& Knowledge, ser. LAK '16. New York, NY, USA: ACM, 2016, pp. 54-63.

[33] I. Khan and A. Pardo, "Data2U: scalable real time student feedback in acive learning environments," in Proceedings of the Sixth International Conference on Learning Analytics \& Knowledge, ser. LAK '16. New York, NY, USA: ACM, 2016, pp. 249-253.

[34] J. de Kraker and R. Cörvers, "European Virtual Seminar on Sustainable Development: international, multi-disciplinary learning in an online social network," E-learning and Education for Sustainability, Series 'Environmental Education, Communication and Sustainability', vol. 35, pp. 117-136, 2014.

[35] A. Slootmaker, M. Scheffel, K. Kreijns, J. De Kraker, and H. Drachsler, "Performance dashboard to support awareness and reflection in elgg communities (version 1.15) [software]," Open Universiteit, Heerlen, The Netherlands, 2015. [Online]. Available: http://hdl.handle.net/1820/6290

[36] H. Drachsler and W. Greller, "Privacy and Analytics - it's a DELICATE issue. A Checklist to establish trusted Learning Analytics," in Proceedings of the Sixth International Conference on Learning Analytics And Knowledge, ser. LAK '16. New York, NY, USA: ACM 2016, pp. 89-98.

[37] R. Hoyle, Structural equation modelling: Concepts, issues, and applications. Thousand Oaks, CA: Sage, 1995.

[38] H. Marsh, J. Bella, and K. Hau, An evaluation of incremental fit indices: A clarification of mathematical and empirical properties. Mahwah, NJ, US: Erlbaum, 1996, pp. 315-353.

[39] M. Browne and R. Cudeck, "Single sample cross-validation indices for covariance structures," Multivariate Behavioral Research, vol. 24, pp. 445-455, 1989.

[40] P. D. Bruyckere, P. A. Kirschner, and C. D. Hulshof, Eds., Urban Myths about Learning and Education. San Diego: Academic Press, 2015.

[41] B. Martynoga, "Head of the class - Teaching methods are often based on convention over evidence. Can neuroscience help pupils to learn?" thelongandshort.org, 2015. [Online]. Available: http://thelongandshort.org/society/ head-of-the-class-neuroscience-education

[42] H. J. Pijeira-Díaz, H. Drachsler, S. Järvelä, and P. A. Kirschner "Investigating collaborative learning success with physiological coupling indices based on electrodermal activity," in Proceedings of the Sixth International Conference on Learning Analytics \& Knowledge, ser. LAK '16. New York, NY, USA: ACM, 2016, pp. 64-73.

[43] M. Scheffel, H. Drachsler, S. Stoyanov, and M. Specht, "Quality Indicators for Learning Analytics," Educational Technology E Society, vol. 17, no. 4, pp. 117-132, 2014. 


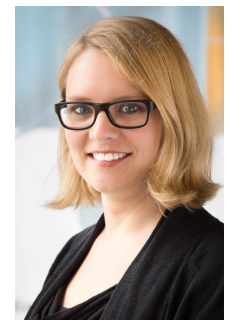

Maren Scheffel is a researcher at the Welten Institute (Research Center for Learning, Teaching and Technology) of the Open University of the Netherlands. She studied computational linguistics at the University of Edinburgh and the University of Bonn and received her M.A. in 2008. She previously worked at the Fraunhofer Institute for Applied Information Technology (FIT) focussing on aspects related to technologyenhanced learning where and was also involved in managing the ROLE project. Since 2014 she has been working at the Welten Institute where she was involved in the management as well as the research for the LACE project and now contributes to the SHEILA project. Her PhD work focuses on creating an evaluation framework for learning analytics. She is a member of the SURF SIG Learning Analytics.

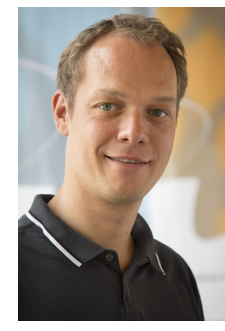

Hendrik Drachsler is Associate Professor for Learning Analytics at the Welten Institute of the Open University of the Netherlands, and holds a Chair on Technology-Enhanced Learning at the University of Applied Sciences Zuyd. His research interests include learning analytics, personalisation technologies, recommender systems, educational data, mobile devices, and their applications in the fields of technology-enhanced learning and health2.0. He is chairing the EATEL SIG dataTEL and the national SIG Learning Analytics of the Dutch umbrella organisation SURF. He is elected member of the Society of Learning Analytics Research (SoLAR). In the past he has been principal investigator and scientific coordinator of various national and EU projects (e.g., laceproject.eu, patient-project.eu, LinkedUp-project.eu). He regularly chairs international scientific events and is Associate Editor of IEEE's Transactions on Learning Technologies, and the Journal of Learning Analytics.

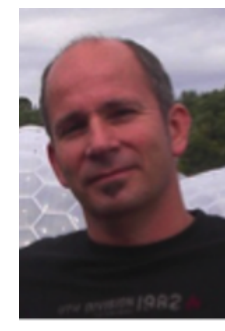

Joop de Kraker is Associate Professor of Environment \& Sustainability at the Faculty of Management, Science \& Technology of the Open University of the Netherlands. He is central coordinator of the European Virtual Seminar on Sustainable Development (EVS) since 2011. His research focusses on 'Learning for Sustainable Development', in particular on collaborative types of learning in formal education and professional practice and how these learning processes can be supported by ICT-tools.

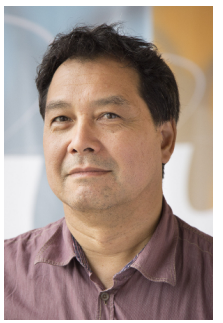

Karel Kreijns is Associate Professor at the Welten Institute of the Open University of the Netherlands. His research interest are (1) the social aspects of computer-supported collaborative learning $(\mathrm{CSCL})$ and networked learning (i.e. social presence, social space, and sociability) using an ecological approach and the affordance theory of Gibson, (2) the application of Self-Determination Theory of Deci and Ryan, the I-Change model of De Vries, and the Reasoned Action Approach framework of Fishbein and Ajzen on teachers' use of technology/open educational resources, enrolling in MOOCs, and teachers' professional development activities (e.g., innovative behaviour, action research, 21 st century skills), and (3) BIE-coaching (BIE = bug-in-ear technology) of beginning teachers to reduce attrition and to improve the quality of the teacher.
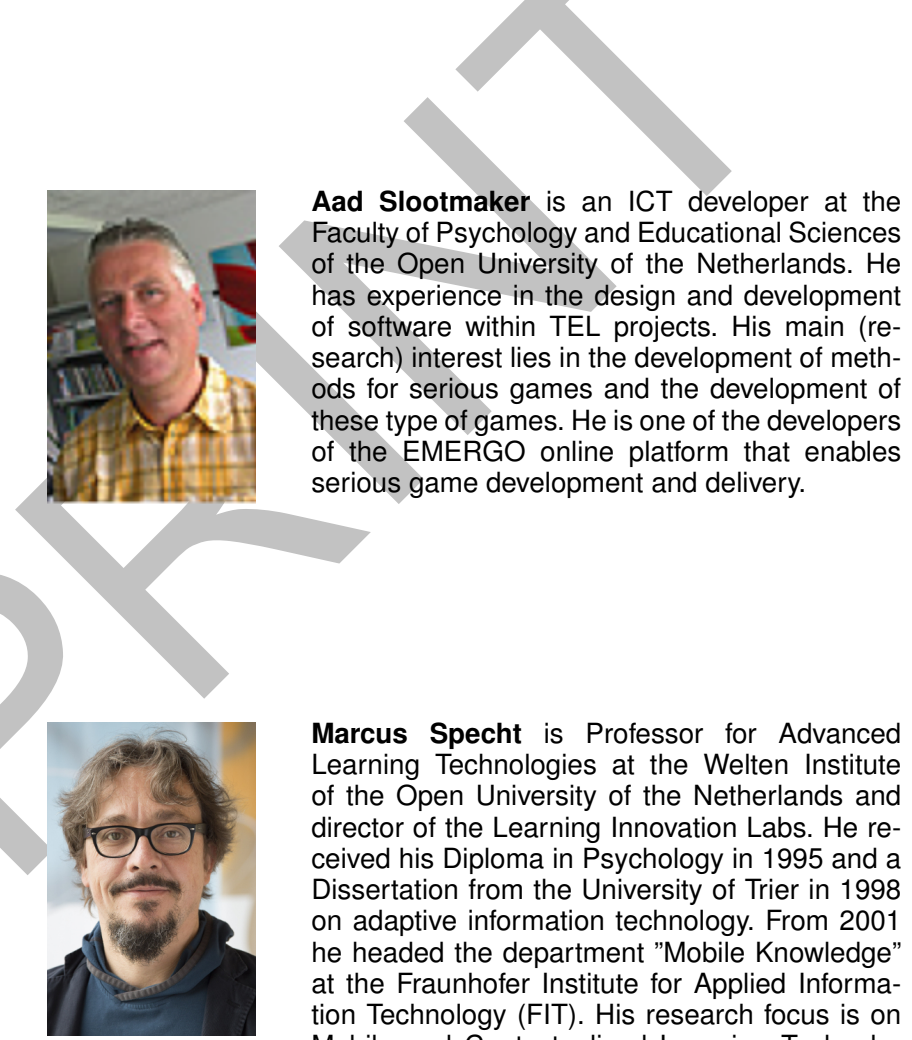

Marcus Specht is Professor for Advanced Learning Technologies at the Welten Institute of the Open University of the Netherlands and director of the Learning Innovation Labs. He received his Diploma in Psychology in 1995 and a Dissertation from the University of Trier in 1998 on adaptive information technology. From 2001 he headed the department "Mobile Knowledge" at the Fraunhofer Institute for Applied Information Technology (FIT). His research focus is on Mobile and Contextualised Learning Technologies and Social and Immersive Media for Learning. Since 2014 he has been Program Chair Technology Enhanced Learning Innovations at the Welten Institute and member of the management team of the Welten Institute. Prof. Specht is a member of ACM, IEEE, the SIKS and ICO research schools in the Netherlands, is an Apple Distinguished Educator and has been President of the International Association of Mobile Learning since 2013. 